\title{
Rheumatology without borders
}

\author{
C-S Lau and PH Feng
}

Advances in immunological research have enabled rheumatology in the West to evolve from a specialty in which poorly defined, supposedly incurable rheumatic diseases are treated, to one that uses sophisticated diagnostic tools and employs targeted, individualized biologic therapies. These advances, however, have not reached many developing countries in Asia, Africa and South America, where millions of patients with rheumatic diseases suffer in silence. These regions lack adequately trained rheumatologists, and rheumatology as a specialty is often unrecognized and unsupported because there are so many other priorities. To lessen the global burden of rheumatic diseases, advances in rheumatology need to cross the borders between developed and developing countries.

There are three ways by which 'rheumatology without borders' can be achieved: first, structured undergraduate musculoskeletal teaching programs are required; second, physicians in this field need to be provided with up-to-date training in clinical and basic rheumatology research; and finally global organizations and national governments should be petitioned for support. Invariably, the prime movers in these endeavors are the rheumatologists, who, therefore, need access to new teaching and research methods, and need to be kept abreast of the latest advances in the treatment of rheumatic diseases.

Interaction with others is the best way to learn. Numerous rheumatology conferences are organized globally, each year, for this purpose. Unfortunately, many clinicians from developing countries cannot afford to attend these meetings, because of the prohibitive cost of registration, air travel and accommodation. For some, attendance at a major congress in Europe or North America could cost a whole year's salary. We urge congress organizers to offer special registration rates and traveling scholarships to registrants from developing countries.
To lessen the global burden of rheumatic diseases, advances in rheumatology need to cross the borders between developed and developing countries

C-S Lau is a member of the Nature Clinical Practice Rheumatology Advisory Board, President of APLAR, and Professor in the Division of Rheumatology and Clinical Immunology at The University of Hong Kong, Hong Kong Special Administrative Region, China. PH Feng is Emeritus Consultant in the Department of Rheumatology, Allergy and Immunology at Tan Tock Seng Hospital, Singapore, and Adjunct Professor of Medicine at the Yong Loo Lin School of Medicine, National University of Singapore.

\section{Competing interests}

The authors declared they have no competing interests.

www.nature.com/clinicalpractice doi:10.1038/ncprheum0509
Getting there is only the first step. The ability to present and discuss one's clinical and research findings with fellow rheumatologists from around the world maximizes the congress experience and helps to improve the quality of research performed in developing countries. Workshops on research methods, scientific writing, and presentation need to be encouraged, as do symposia on rheumatic diseases that present various regional perspectives.

An alternative and cost-effective way to enable rheumatologists from developing countries to benefit from the conference experience is to bring world leaders in rheumatology to those developing regions. The Asia Autoimmunity Forum is a prime example of a congress that brings renowned scientists to a convenient city in Asia with a target audience of clinical researchers and trainees in the field of autoimmunity (http://www.aaf2007.org/). This nonprofit meeting is held annually, and has minimal registration and accommodation costs. Being a small meeting, it is also an excellent platform for young rheumatologists to interact and exchange ideas with the best minds in the discipline.

Similar initiatives could be started with rheumatology journals. Publishers could consider special subscription rates for clinicians from developing countries, and scientists from these regions could be invited to join editorial boards so that they can learn about publishing and provide a regional perspective on various rheumatic diseases. Working with local and regional journals should be encouraged, so that highquality articles that appear in these journals can be published in a summary format in the international press, and vice versa.

There are many ways to encourage rheumatology to cross geographical, language, cultural, social and economic borders. We hope the rheumatology community from the West will not view this process as a burden, but as a stimulus to ensure the global growth and enrichment of our specialty. 